\title{
REHABILITATION OF AN AMPUTATED FINGER- A CASE REPORT
}

\author{
Saumya Sharma ${ }^{1}$, Gulab Chand Baid ${ }^{2}$, Vivek Lath ${ }^{3}$,Neeraj Gupta ${ }^{4}$, Subhash Chandra Pankaj ${ }^{5}$
}

1 Professor, Maitri College of Dentistry and Research Centre, Anjora, Durg, Chhattisgarh.

${ }^{2}$ Reader, Maitri College of Dentistry and Research Centre, Anjora, Durg, Chhattisgarh.

${ }^{3}$ Senior Lecturer, Maitri College of Dentistry and Research Centre, Anjora, Durg, Chhattisgarh.

${ }^{4}$ Senior Lecturer, Maitri College of Dentistry and Research Centre, Anjora, Durg, Chhattisgarh.

5 Postgraduate Student, Maitri College of Dentistry and Research Centre, Anjora, Durg, Chhattisgarh.

\section{ABSTRACT}

\section{BACKGROUND}

Aesthetic prosthesis offers psychological, functional and rehabilitative advantages. By restoring the natural appearance of hand and finger, the prosthesis eliminates the trauma caused by constant reminder of handicap and thus offers true psychological therapy. A precisely fitting finger prosthesis improves the function by restoring the normal length, maintaining sensitivity, protecting the sensitive stump, transmitting pressure and position sense and returning the patient's confidence. The definition of function here is an interesting one, because surely if a patient is using prosthesis for cosmetic reasons then it is serving a function. Although implant supported finger prosthesis definitely has a superior outcome, it is not advisable in all patients due to economic grounds. This article focuses a method of retaining finger prosthesis.

\section{KEYWORDS}

Amputee, Hand, Prosthesis, Silicon.

HOW TO CITE THIS ARTICLE: Sharma S, Baid GC, Lath V, et al. Rehabilitation of an amputated finger- A case report. J. Evolution Med. Dent. Sci. 2017;6(9):744-748, DOI: 10.14260/Jemds/2017/161

\section{BACKGROUND}

Both function and form are important attributes of the hand. Hands may be affected by many conditions varying from congenital abnormalities to diseases, but the greatest cause of functional impairment is trauma.1,2 Traumatic amputation represents not only serious insult to hand, but also to the psychology of the individual. Many times severely injured and traumatically amputated fingers can be saved by microsurgical re-implantation. In some patients reconstruction is contraindicated, in these patients prosthesis is provided and offers great psychological help. ${ }^{3}$

Aesthetic prosthesis offers psychological, functional and rehabilitative advantages. By restoring the natural appearance of hand and finger, the prosthesis eliminates the trauma caused by constant reminder of handicap and thus offers true psychological therapy. ${ }^{2}$ A precisely fitting finger prosthesis improves the function by restoring the normal length, maintaining sensitivity, protecting the sensitive stump, transmitting pressure and position sense and returning the patient's confidence. The definition of function is an interesting one, because surely if a patient is using prosthesis for cosmetic reasons then it is serving a function. 4 Therefore, both the psychological and functional effects of prosthesis enhance rehabilitation by helping patients to their loss. ${ }^{5}$

\section{CASE REPORT}

A 48-year-old patient who lost his little finger of left hand in an accident reported for treatment [Fig. 1].

Financial or Other, Competing Interest: None.

Submission 23-12-2016, Peer Review 15-01-2017,

Acceptance 23-01-2017, Published 30-01-2017.

Corresponding Author:

Dr. Subhash Chandra Pankaj,

QT-9/A, Street-1/A,

Sector-10, Bhilai Nagar, Durg, Chhattisgarh.

E-mail:docsubhash23@gmail.com

DOI: $10.14260 /$ jemds $/ 2017 / 161$

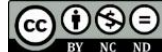

An informed consent was taken from the patient before starting the treatment to ensure his willingness.

\section{Technique \\ Hand Impression}

The patient's hand was lubricated with a thin layer of petroleum jelly. The patient was instructed to stand in relaxed position. A plastic lid was used to place the patient's hand and make the impression. A thin mix of alginate (Neocolloid, Zhermack) was painted over the impression surface and impressions were made [Fig. 2]. A thin layer of dental plaster was then painted over the alginate to reinforce the impression [Fig. 3]. The impression was then poured in dental stone (Kalastone, Kalabhai Dental Pvt. Ltd.) and working cast was retrieved.

\section{Wax Glove Technique Utilising Donor Pattern}

Patient's right hand was chosen as a donor hand and impression of donor site was made [Fig. 4]. The impression was poured in wax (Modelling wax, Dental products of India Ltd.) allowing the wax to cool before pouring, to ensure good consolidation and reproduction of detail.

\section{Nail Bed Preparation}

An artificial nail which is used for cosmetic purposes was used in place of acrylic teeth. A metal loop of $U$ shape was attached at the back of the artificial nail and attached with cold cure clear acrylic resin to achieve retention and an undercut was created beneath the cuticle margin to retain the artificial nail [Fig. 5].

\section{Retention}

Adjacent finger i.e. ring finger was planned to be used for retention of the prosthesis. As the patient had the stump of little finger also, two iron rings were joined to each other with one retentive loop with the ring to receive silicon [Fig. 6a, 6b]. 
Wax pattern of donor site was adjusted according to the site and retentive ring was placed in accordance with wax-up [Fig. 7a, 7b, 7c]. Try in was done to ensure proper fit, stability and seating of wax pattern [Fig. 8].

\section{Investment Technique}

The pattern was flasked in conventional flasks using dental plaster, using two pour techniques. The first pour was done till the junction of dorsal and ventral surface of the prosthesis. The retentive ring was completely embedded in the first pour. When set, the wax was boiled out and the mould was opened carefully. Separating medium was applied between the two pours in preparation for loading the mould with silicon [Fig. 9].

\section{Colour Matching}

The silicon (RTV) was matched intrinsically to match with patient's skin. The advantage of intrinsic staining are increased service life of the prosthesis and planned translucency. Coloured silicon was layered into the mould and packing was done. The moulds were closed and transferred to the clamp. The silicon was processed at room temperature. After the stipulated time mould was opened carefully and excess material was trimmed with scissors. The fit and shade was evaluated on the patient. Extrinsic colouration was applied on some areas for further colour matching [Fig. 10a, 10b].

The prosthesis was inserted and the patient was instructed on the maintenance of the prosthesis.

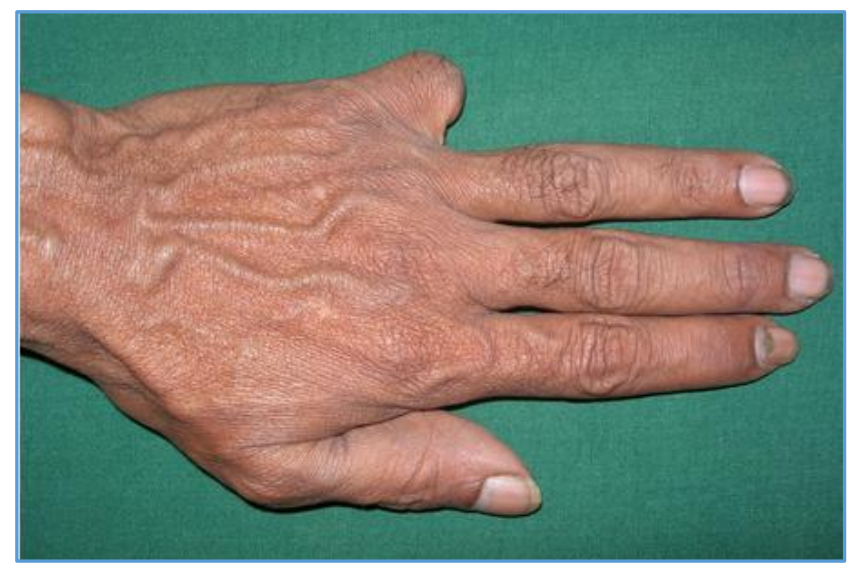

Figure 1. Pre-prosthetic View of Defect

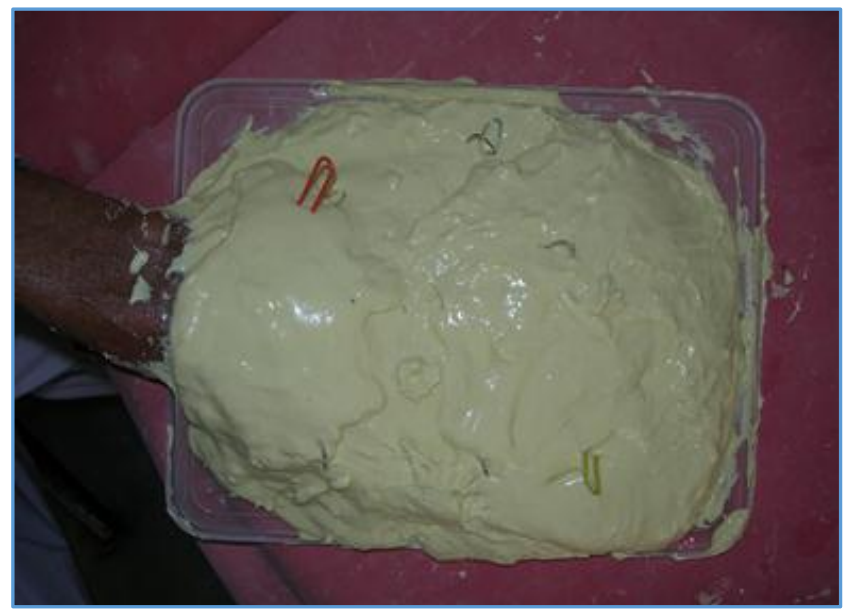

Figure 2. Impression of Defective Hand

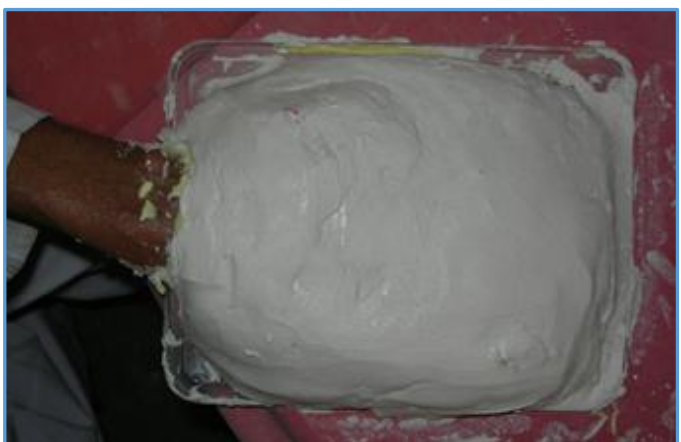

Figure 3. Impression Reinforced with Plaster

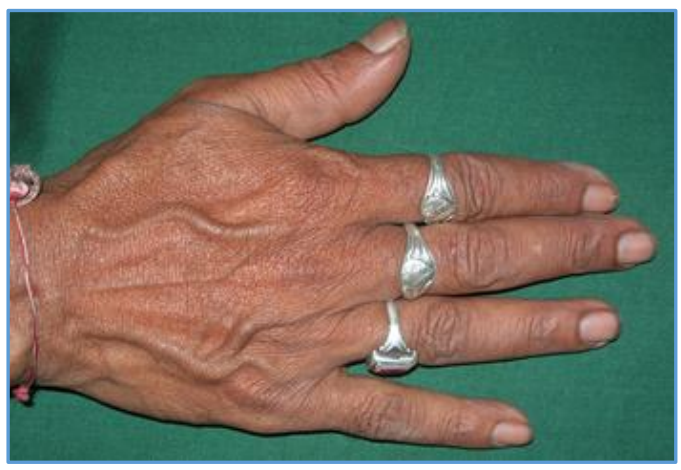

Figure 4. Donor Hand

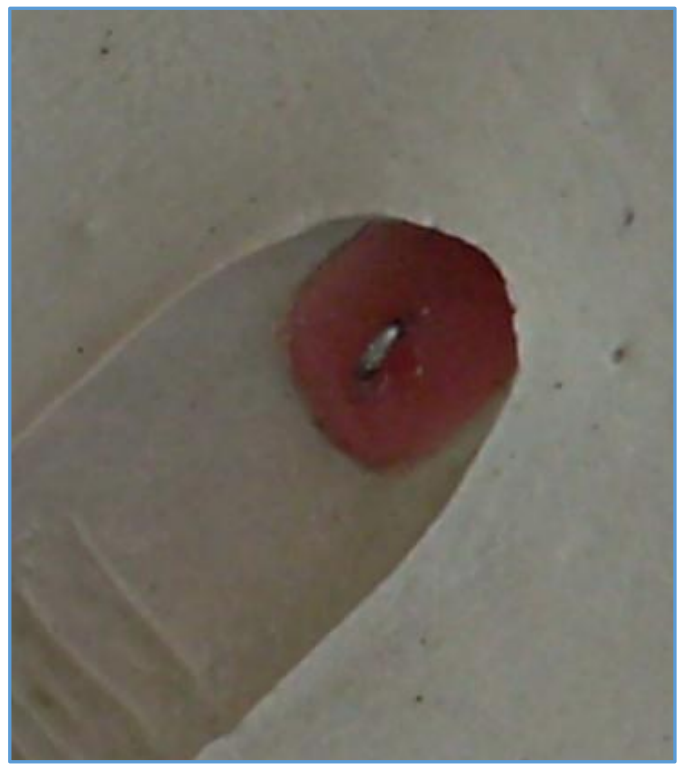

Figure 5. Retentive Loop attached to the Artificial Nail

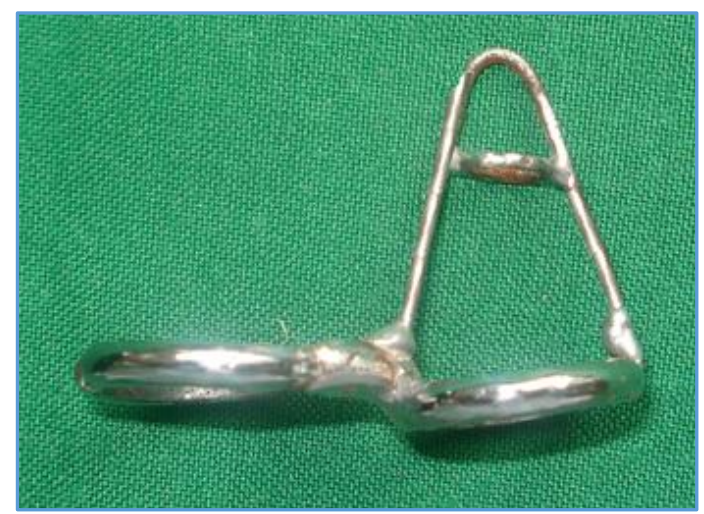

Figure 6a. Retentive Ring Design 

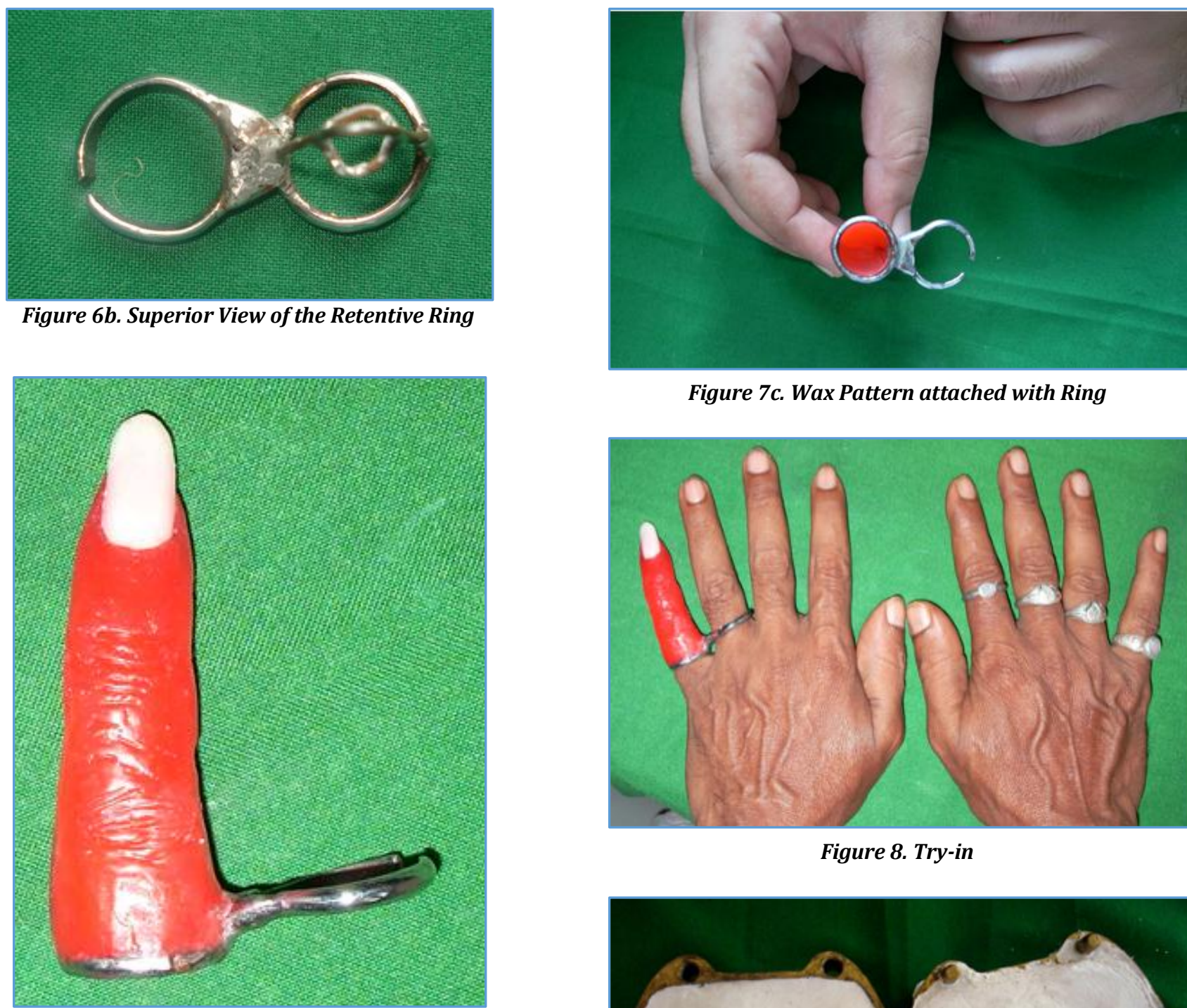

Figure 7c. Wax Pattern attached with Ring

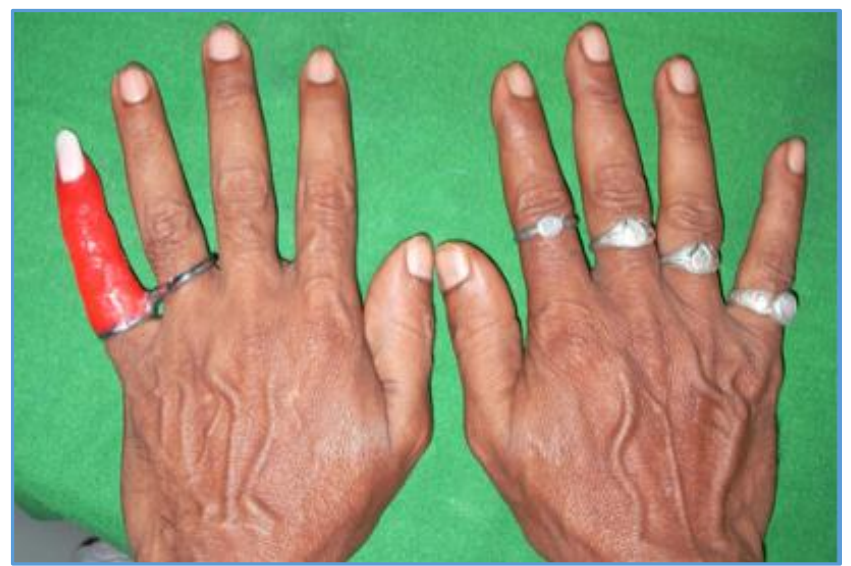

Figure 8. Try-in

Figure 7a. Wax Pattern attached with Ring (Dorsal View)

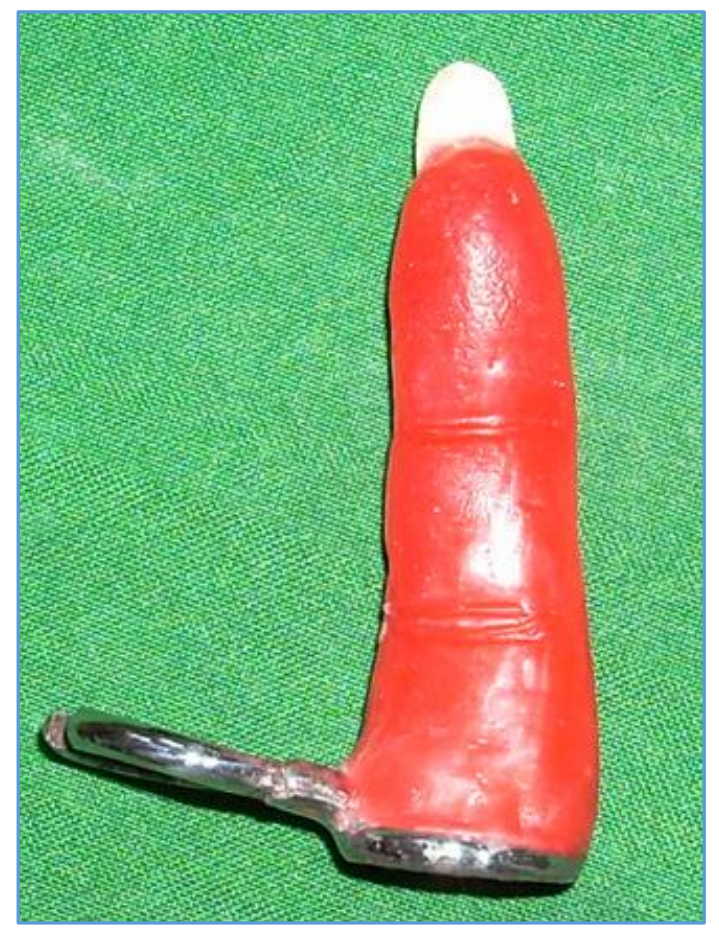

Figure 7b. Wax Pattern attached with Ring (Ventral view)

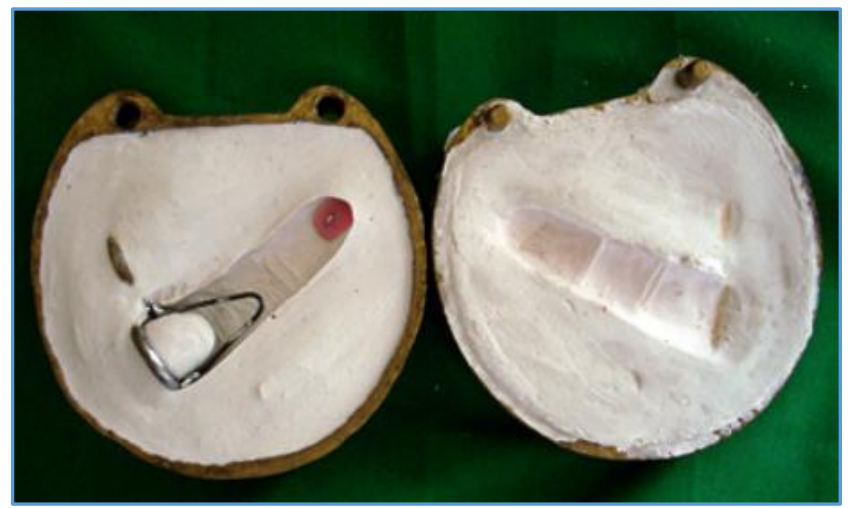

Figure 9. Dewaxed Investment

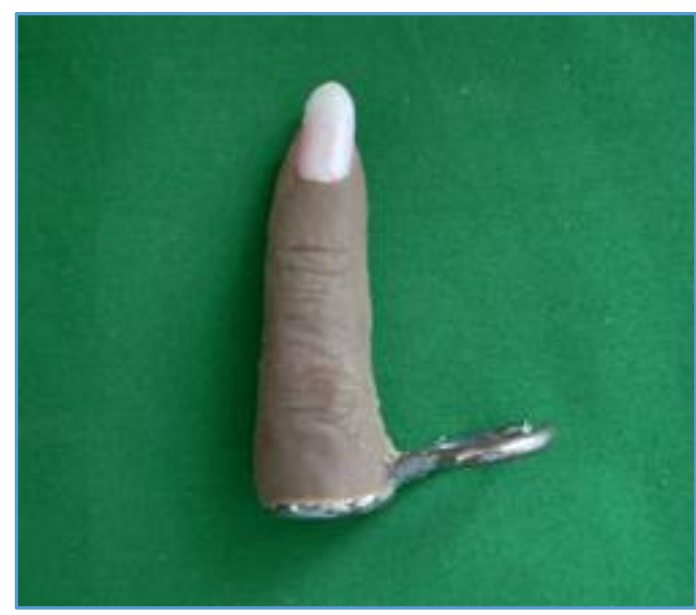

Figure 10a. Completed Prosthesis (Dorsal view) 


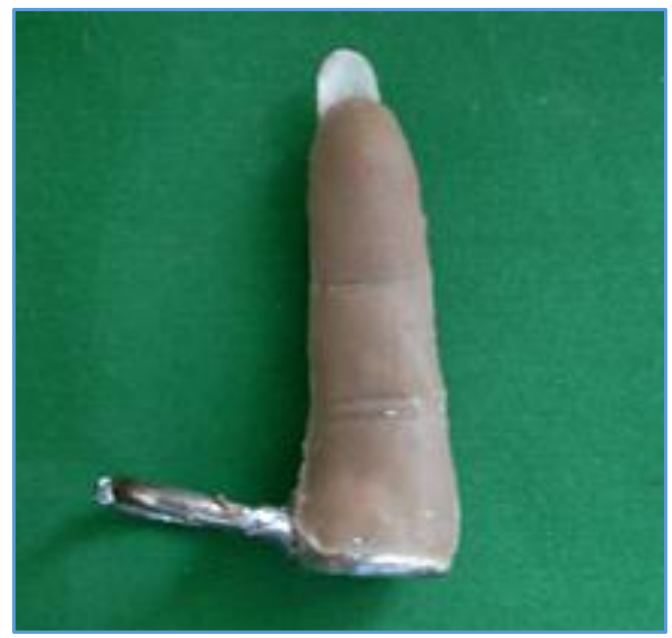

Figure 10b. Completed Prosthesis (Ventral View)

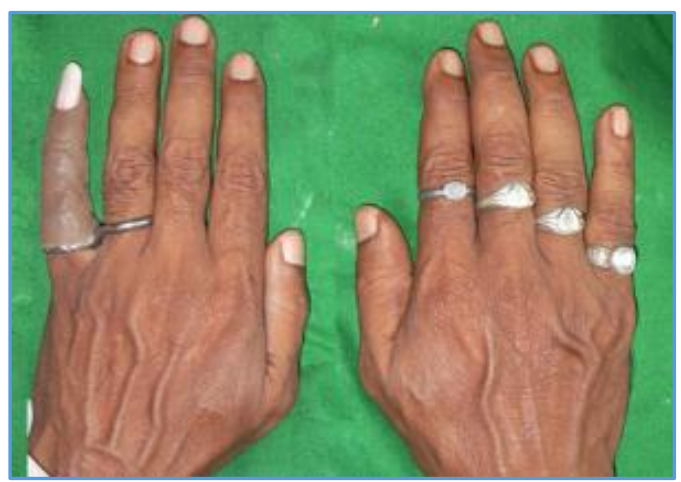

Figure 11. Post prosthetic View of Patient's Hand

\section{DISCUSSION}

The amputation of one or more fingers of the hand, as the consequence of trauma or congenital absence of one or more phalanges, carries a serious reduction of hand function and social dysfunction for the patient. 6 Many injuries and traumatic amputations of fingers can be rescued by microsurgery through re-implantation.

Although there are various ways to medically and surgically manage digital amputations, the goals of rehabilitation remain the same: preserve the functional length, preserve useful sensitivity, prevent symptomatic neuromas, prevent adjacent joint contractures, achieve shortduration morbidity, and enable the patient to perform tasks of daily life as quickly as possible. ${ }^{7}$

Success of prosthesis depends on the precision in planning, making the impression, carving the model and choosing the material that best suits the circumstances. Issues that clinicians should attend to include: (1) amputation is a diverse disability; (2) discrimination by others; (3) selfstigma; (4) feeling vulnerable to victimisation and (5) the role of values, meaning and perspective in positive adjustment.8,9,10

Materials available for maxillofacial prosthesis are ${ }^{10,11}$ acrylic resin, acrylic copolymers, polyvinyl chloride copolymers, chlorinated polyethylene, polyurethane elastomers, etc.

Very commonly used materials include medical grade silicones, polymethyl acrylics, etc. ${ }^{11}$ Former being commonly used and preferred material for mimicking the tissue structures and the consistency for a life-like appearance and the perception. Silicones are synthetic polymeric chains where silicone atoms bonded to organic groups typically methyl groups. ${ }^{12}$

\section{Classification $9,11,12$}

Silicones are classified into four groups according to their applications-

\section{Class I}

Implant grade, which requires the material to undergo extensive testing and must meet Food and Drug Administration requirements.

\section{Class II}

Medical grade, which is approved for external use. This material is used for fabrication of maxillofacial prosthesis (used in our case).

\section{Class III}

Clean grade.

\section{Class IV}

Industrial grade, commonly used for industrial applications.

Various silicones are available for maxillofacial prosthesis such as HTV Silicones, RTV Silicones, MDX 4-4210, etc. We used HTV Silicones for fabrication of prosthesis. This is because of their outstanding properties over other silicone materials, which includes a wide range of service temperatures $\left(-50^{\circ} \mathrm{C}\right.$ to $200^{\circ} \mathrm{C}$, or even $-90^{\circ} \mathrm{C}$ to $300^{\circ} \mathrm{C}$ for special formulations), no known physical or physiological harmful effects, excellent ageing resistance, excellent thermal stability and stable colour. 13 of course, it has shortcomings such as not adequately elastic in function, low edge strength and opacity. ${ }^{11}$

Recently, some advanced silicone materials have become available for prosthesis such as silicone block copolymers, foaming silicones, etc which overcome the drawbacks of HTV silicones ${ }^{14}$.

There are various methods to increase the retention of the prosthesis such as the use of retentive finger rings, 15,16 medical grade adhesives, 17 implants, ${ }^{3}$ etc along with the basic positive contact of the prosthesis with the tissues. Leow et al ${ }^{18}$ studied optimal circumference reduction of finger models for a good prosthetic fit of a thimble-type prosthesis for distal finger amputations and found out that 5-7\% circumference reduction in the finger was shown to be best among 1-3\% and $8-9 \%$ of reduction. 18

\section{Recent Advances ${ }^{19}$}

In the present scenario, intelligent dexterous prosthetic hands are developed which are capable of individual controllable fingers and thumbs which can abduct or adduct which allow implementation of many different grasping strategies. Smart Hand and i-limb are few of these highly sophisticated prosthetic hands available.

Today's technology permits fabrication of a finger prosthesis even in the absence of the physical presence of the patient. The research has been successfully carried out by Cabibihan ${ }^{19}$ and his team where computer-based design and fabrication of the prosthesis was performed to accurately replicate the patient's finger characteristics at the same time reducing the number of patient visits but the prosthesis fit was achieved by traditionally impressing the stump on stereolithography models. ${ }^{19}$ The cost and affordability by the patient limits the use of this technology. 

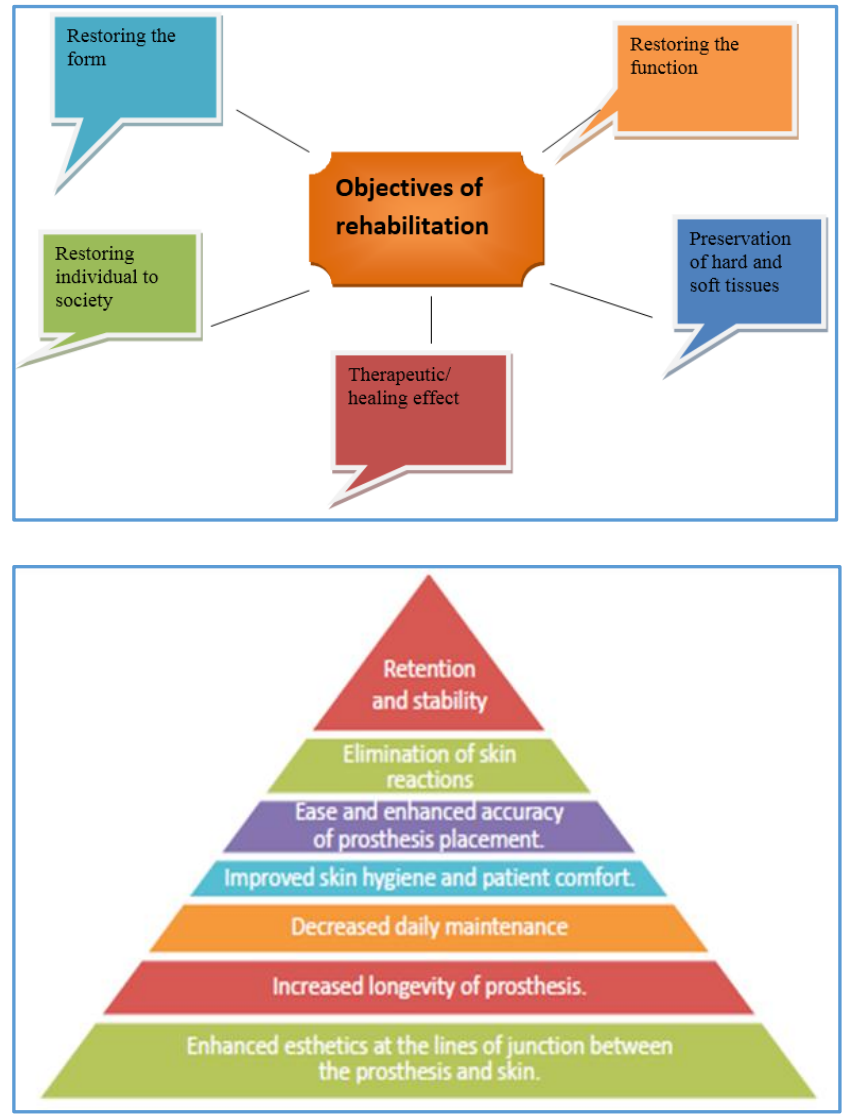

Post-Rehabilitation Instruction to the Patient

1. Before placing the prosthesis apply a thin layer of water base lubricant to the underlying skin and gently place the prosthesis.

2. Do not wear the prosthesis overnight as it may cause irritation to the skin.

3. Wash prosthesis every day with a mild soap. Avoid exposure of prosthesis to high temperature.

\section{Learning points}

- Success of prosthesis depends on the precision in planning, making the impression, carving the model and choosing the material that best suits the circumstances.

- Acceptance of prosthesis depends heavily on its ability to effectively represent the appearance and comfort.

- In this technique, positive pressure was distributed evenly based on the capability of the tissues to withstand the compressibility and was added by a retentive finger ring which also solved the purpose of retention and aesthetics.

- Use of implants for the rehabilitation in this particular case would have been more appropriate keeping out the financial constraints due to a short stump.

\section{CONCLUSION}

Due to various debilitations majority of the cases report with compromised conditions. The best of efforts is required to make even small amount of improvement in the quality of life of these individuals.
A figure prosthesis, in this case not only improved aesthetics but also contributed immensely to the physical and mental well-being of the patient.

\section{REFERENCES}

[1] Pereira BP, Kour KL, Leow EL, et al. Benfits and use of digital prostheses. J Hand Surg AM 1996;21(2):222-8.

[2] Pillet J. Esthetic hand prostheses. J Hand Surg AM 1983;8[5 Pt 2]:778-81.

[3] Aydin C, Karakoca S, Yilmaz H. Implant-retained digital prostheses with custom-designed attachments: a clinical report. J Prosthet Dent 2007;97(4):191-5.

[4] Pillet J. The aesthetic hand prosthesis. Orthop Clin North Am 1981;12(4):961-9.

[5] Taylor TD. Facial prosthesis fabrication: technical aspects clinical maxillofacial prosthesis. Chicago: Quintessence Publishing Company 2000.

[6] Cervelli V, Bottini DJ, Arpino A, et al. Bone anchored implant in cosmetic finger reconstruction. Ann Chir Plast Esthet 2008;53(4):365-7.

[7] Ware LC. Digital amputation and ray resection. In: Clark CL, Wilgis EF, Aiello B, et al, eds. Hand rehabilitation: a practical guide. $2^{\text {nd }}$ edn. New York: Churchill Livingstone 1998.

[8] Taylor TD. Clinical maxillofacial prosthetics. London: Quintessence Publishing Company 2000.

[9] Thomas FK. Prosthetic rehabilitation. London: Quintessence Publishing Company 1994.

[10] Chalian VA, Drane JB. Maxillofacial prostheticsmultidisciplinary practice. Baltimore: William and Wilkins Company 1972.

[11] Maller US, Karthik KS, Maller SV. Maxillofacial prosthetic materials-past and present trends. JIADS 2010;1:25-30.

[12] Laney WR. Maxillofacial prosthetics. PSG Publishing Company 1979.

[13] Beumer J, Curtis TA, Marunick M. Maxillofacial rehabilitation: prosthodontic and surgical considerations. J Oral and Maxillofacial Surg 1997;55(7):786.

[14] Raghu KM, Gururaju CR, Sundaresh KJ, et al. Aesthetic finger prosthesis with silicone biomaterial. BMJ Case Reports 2013:1-5.

[15] Shweta D, Saurabh L, Farhan S. Fabrication of a glove type finger prosthesis using silicone elastomers. J Indian Prosthodont Soc 2008;8(3):165-8.

[16] Nazir S, Gangadhar SA, Manvi S. Fabrication of silicone finger prosthesis: a clinical report. J Indian Prosthodont Soc 2006;6(4):199-201.

[17] Pylios T, Shephard DE. Wear of medical grade silicone rubber against titanium and ultrahigh molecular weight polyethylene. J Biomed Res Part B Appl Biomater 2008;84(2):520-3.

[18] Leow ME, Prosthetist C, Pho RW. Optimal circumference reduction of finger models for good prosthetic fit of a thimble-type prosthesis for distal finger amputations. J Rehabil Res Dev 2001;38(2):273-9.

[19] Cabibihan JJ. Patient-specific prosthetic fingers by remote collaboration-a case study. PLoS ONE 2011;6(5):e19508. 